\title{
Adsorption studies for the removal heavy metal by chitosan-g-poly (acrylicacid-co-acrylamide) composite
}

\author{
Shyam R. Khairkar, Arun R. Raut \\ Dept. of Chemistry, Govt. Institute of Science \& Humanities Amravati, Amravati, India 444606
}

\section{Email address:}

Shyamkhairkar@gmail.com (Shyam R. K.)

\section{To cite this article:}

Shyam R. Khairkar, Arun R. Raut. Adsorption Studies for the Removal Heavy Metal by Chitosan-G-Poly (Acrylicacid-Co-Acrylamide) Composite. Science Journal of Analytical Chemistry. Vol. 2, No. 6, 2014, pp. 67-70. doi: 10.11648/j.sjac.20140206.12

\begin{abstract}
In present research work natural bio polymer "Chitosan" was grafted onto Acrylic acid and Acrylamide and adsorption of some heavy metal studied by batch method. Synthesis of grafted chitosan supersorbent was synthesized by radical polymerization method. The adsorption of heavy metal cations, $\mathrm{Cu}(\mathrm{II}), \mathrm{Cd}(\mathrm{II}), \mathrm{Ni}(\mathrm{II})$, and $\mathrm{Pb}$ (II) from aqueous solution by newly-synthesized superabsorbent composite of chitosan-g-poly (acrylicacid-co-acrylamide) was investigated. The superabsorbent gel was characterized on the basis of FTIR, X-ray differation, Scanning electron Microscopy and thermal properties. The percentage adsorptions of metal ions on adsorbent were determined by batch methods using atomic absorption spectrophotometry (AAS). The effect of experimental parameters, such as $\mathrm{pH}$, treatment time, temperature, adsorbent dose, initial metal ion concentration on the removal of metal ions was also studied. Chitosan-g-poly (acrylicacid-co-acrylamide) proved to be an effective adsorbent for the removal of different heavy metal ions from aqueous solution.
\end{abstract}

Keywords: Chitosan, Superabsorbent, Acrylamide, Acrylic Acid, Heavymetal, Bio-Adsorption

\section{Introduction}

Toxic metals can be distinguished from other pollutants, since they are not biodegradable and can be accumulated in nature. The complete removal of toxic heavy metal ions that are incompatible with biological systems requires expensive treatment in order to produce water that is again useful for domestic use (1)It is essential to extend methods for removal of metal ions to decrease the pollution load on the environment. Classical techniques of heavy metal removal from solutions include the following processes: solvent extraction, precipitation and co-precipitation, electrochemical reduction, chemical- and biosorption, pre-concentration.

In recent years, the adsorption process has also received much attention and has become one of the more popular methods for the removal of heavy metal ions from wastewater, because of its competitive and effective process. Numerous adsorbents have been reported for the removal of toxic metal ions, such as chitin, chitosan, starch, cellulose, guaran, and cyclodextrin, which are not only eco-friendly and costeffective but are also effective in remediation of common effluents present in wastewater. Other polysaccharide-based materials and alumino-silicates are used as adsorbents in wastewater treatment. Adsorption using commercial activated carbon.
However, CAC is an expensive material. Resins prepared with divinyl benzene-styrene backbone are hydrophobic.These resins, prepared from petrochemicals, are costly. Their ion exchange capacity depends mainly on the quantity of functional groups and the $\mathrm{pH}$ of the solution. The most widespread chelating functional groups used for removal of metal ions from effluents are thiol, thiourea, dithionite, aspartate and triisobutyl phosphine sulphide.

The main purpose of this work was to determine the percentage of sorption of different heavy metal on newly synthesized Chitosan-g-poly (acrylicacid-co-acrylamide) composite sorbent.

\section{Material and Methods}

\subsection{Materials}

Chitosan (from Sigma Aldrich Mol wt. 22742 Da and degree of deacetylation of 0.75), Acrylic acid (AA, Merck) and acrylamide (AM, Merck) were used after vacuum distillation. Ammonium persulfate (APS, Merck) was used without purification. Methylenebisacrylamide (MBA, Fluka) was used as received. $\mathrm{pH}$ Buffer tablet ( $\mathrm{pH} 1$ to 6) ,All reagents were analytical grade and were used without further purification. 


\section{Chemical and Reagents}

Stock solutions of copper chloride, cobalt chloride, lead nitrate and nickel chloride of $100 \mathrm{mg} / \mathrm{l}$ were used as adsorbate, and solutions of various concentrations were obtained by diluting the stock solution with distilled water. Copper Cobalt, and Nickel concentrations were determined by AAS. All the chemicals used were of analytical grade reagent and all experiments were carried out in $500 \mathrm{ml}$ glass bottles at the laboratory ambient temperature of $25^{\circ} \mathrm{C}$.

\section{Preparation of Adsorbents}

Chitosan solution was prepared in assembly equipped with mechanical stirrer and gas inlet. Chitosan was dissolved in degassed distillated water containing $1 \mathrm{wt} \%$ of acetic acid. In general, $0.50 \mathrm{~g}$ of chitosan was dissolved in $30.0 \mathrm{ml}$ of distillated degassed $1 \mathrm{wt} . \%$ acetic acid solution. The reactor was placed in a water bath preset at $60^{\circ} \mathrm{C}$. Then $0.10 \mathrm{~g}$ of KPS as an initiator was added to chitosan solution and was allowed to stir for $10 \mathrm{~min}$ at $60^{\circ} \mathrm{C}$. After adding $\mathrm{KPS}, 0.5 \mathrm{ml}$ of AA and $0.5 \mathrm{gm}$ of AAm were added simultaneously to the chitosan solution. MBA solution $(0.1 \mathrm{~g}$ in $5 \mathrm{ml} \mathrm{H} 2 \mathrm{O})$ was added to the reaction mixture after the addition of monomers and the mixture was continuously stirred $(600 \mathrm{rpm})$ for $1 \mathrm{~h}$ under nitrogen. After $60 \mathrm{~min}$, the reaction product was allowed to cool to ambient temperature and neutralized to $\mathrm{pH}$ 8 by addition of $1 \mathrm{~N} \mathrm{NaOH}$ solution. Methanol $(500 \mathrm{ml})$ was added to the gelled product while stirring. After complete dewatering for $24 \mathrm{~h}$, the hardened gel particles product were filtered, washed with fresh methanol and dried at $50^{\circ} \mathrm{C}$. (2) Dried product Chitosan-aa-am sorbent is then sieved through 60 Mesh Particle size for better and uniform adsorption study by batch method.

\section{Characterization of Adsorbents (Chito-AA-AM) Composite}

The new material was well characterized by elemental analysis, FT-IR spectra, Differational scanning colourimentry (DSC), XRD and scanning electron microscopy (SEM). The new sorbent surface exhibits good chemical and thermal stability. IR analysis indicates enviourment of $-\mathrm{OH}$ from chitosan backbone in the grafting which is indicating by broad band $3342 \mathrm{~cm}^{-1}$.DSC indicates crystalline nature of composite.XRD studies conforms the composite bonding which may be intra or intermolecular.SEM indicates porous structure \& support permeation of water molecule in sorbent composite.(3-5) SEM indicates porous structure \& support permeation of water molecule in hydrogel, inversion supports the applicability of such smart material in drug delivery, biomedical material and analytical chemistry. Also the swelling study of gels reveals that the gels are have variable swelling behavior at different $\mathrm{pH}$ solutions. The gels used in present investigation have polyamphophilic network which intelligently gives response to $\mathrm{pH}$ change. Thus these gels may be considered as excellent advanced material for sustainable development in field of analytical chemistry.

\section{Methodology}

\subsection{Batch Sorption Experiments}

All the sorption experiments were performed at $25{ }^{\circ} \mathrm{C}$ and $150 \mathrm{rpm}$ for on an orbital shaker with $100 \mathrm{mg}$ of the sorbent in a $250 \mathrm{~mL}$ flask containing $100 \mathrm{~mL}$ of copper, cadmium, nickel and lead solution with 30 min shaking time. Batch adsorption experiments were conducted to examine the sorption kinetics and equilibrium. In the sorption kinetic experiments, a $1 \mathrm{ppm}$ of copper, nickel, lead cadmium solution at different initial solution pHs was used. In the sorption isotherm experiments conducted over $24 \mathrm{~h}$, the initial solution $\mathrm{pH}$ was adjusted to 5, with $100 \mathrm{mg}$ of sorbent in $100 \mathrm{~mL}$ of metal solution at various concentrations. Same procedure was repeat by adjusting $\mathrm{pH}$ 4,3,2 and 1 using buffer tablet. After sorption, the sorbent was separated from the solution by membrane filtration, rinsed with DI water, (6-8) while The metal concentration in the filtrate was analyzed using a flame atomic absorption spectrophotometer AAnalyst200 (Perkin Elmer, USA) All the sorption experiments were conducted in duplicate, and the mean values were reported. As 1 ppm (100 microgram per 100 $\mathrm{ml}$ ) metal loaded for batch study of metal sorption then decreasing metal conceration from aq. Phase is calculated in percentages format ( Fig 1 to 4).

\section{Result and Conclusion}

\subsection{Sorption Kinetics Study}

Graph shows the sorption kinetics of copper, nickel, lead and cadmium ions using the sorbent composite at different solution pHs. The sorption of both the metals was timedependent. The sorption kinetics of copper was rapid in the first $60 \mathrm{~min}$, before becoming more gradual until equilibrium was reached. At $\mathrm{pH} 4$ and $\mathrm{pH} 5$, the equilibrium for copper sorption was attained within 120 and 180 min, respectively. In cadmium sorption, the sorption kinetics was similar. As the sorbent surface is bare in the initial stage, the sorption kinetics is fast and normally governed by the diffusion process from the bulk solution to the surface. In the later stage, the sorption is likely an attachment-controlled process due to less available adsorption sites.(9-10)

\subsection{Effect of pH on Metal Sorption}

$\mathrm{pH}$ is an important parameter that affects metal ion sorption; it not only influences the properties of sorbent surface but also affects metal speciation in solution. In our experiments, the initial solution pHs at 5.0 and 6.0 for copper metal (Fig 1) gives 80-90\% of metal extraction. But for cadmium in get adsorbed higher at $\mathrm{pH} 4$ (Fig 2). The sorption capacity increased with an increase in initial pH upto pH-6. The final solution $\mathrm{pH}$ after $24 \mathrm{~h}$ of sorption (shown in Figure 1) The results of the kinetics of copper sorption on the sorbent at $\mathrm{pH} 5$ without $\mathrm{pH}$ adjustment during the sorption 
process revealed that the sorption was rapid and the equilibrium was achieved within 30 min.In Nickel sorption, the sorption capacity increased with increasing $\mathrm{pH}$ of solution at $\mathrm{pH}-5$ to 6(Fig no.3). The effect of $\mathrm{pH}$ on lead sorption, presented in (Figure 4), shows a similar increase in sorption capacity with at $\mathrm{pH} 3$ to 5 . A sorption capacity of was achieved at $\mathrm{pH}$ 6.(11-14)

\subsection{Effect of Adsorbent Dose}

The dependence of metal adsorption was studied by varying the amount of adsorbent from 100 to $600 \mathrm{mg}$, while keeping other parameters ( $\mathrm{pH}$, and contact time) constant. From Figure 5, it was observed that with the fixed metal concentration, it can easily be inferred that the percent removal of metal ions increases with increase in adsorbent dose. This initial increase of percent removal of heavy metal ions with increase in adsorbent dose was due to the greater availability of exchangeable sites for the metal ions.

\subsection{Effect of Contact time}

The effect of contact time was represented in the figure- 6 . It shows that the removal of metal ion increases with increase in contact time upto 1 hour and remained constant (75.2\%) from 325 to 350 mins. This may be due to the availability of larger surface area for the metals. The initial removal occurs immediately as soon as the metal and grafted copolymer came into contact and after some extent further increase in contact time did not increase the uptake which was due to decrease of the easily available active sites for adsorption till the equilibrium is reached.

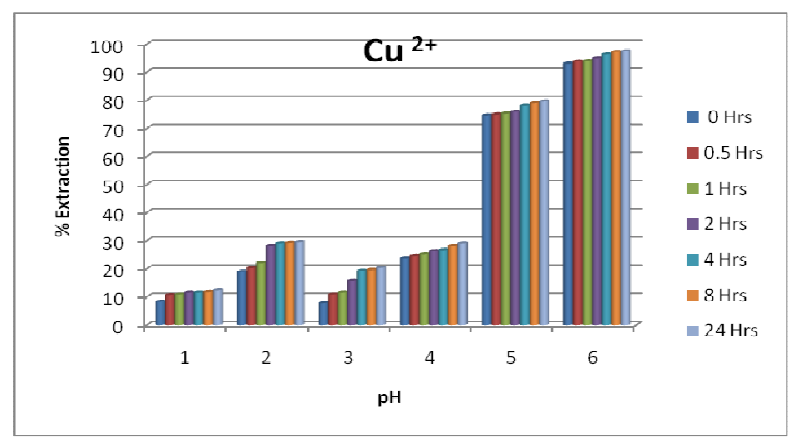

Fig. 1. \% Extraction of Copper Metal ion at different $p H$

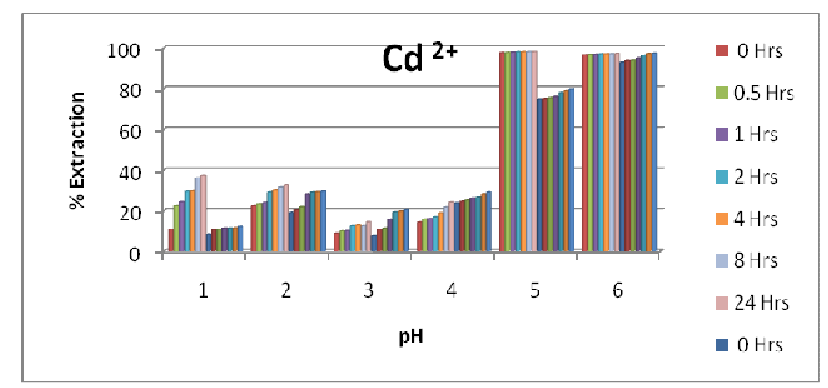

Fig. 2. \% Extraction of Cadmium Metal ion at different $p H$

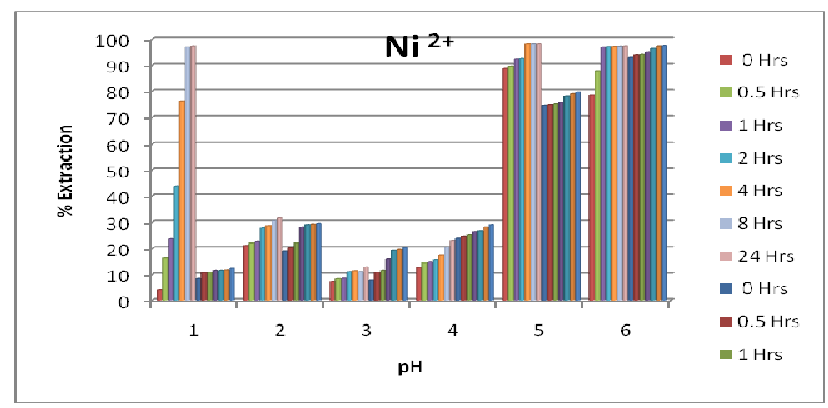

Fig. 3. \% Extraction of Nickel Metal ion at different $p H$

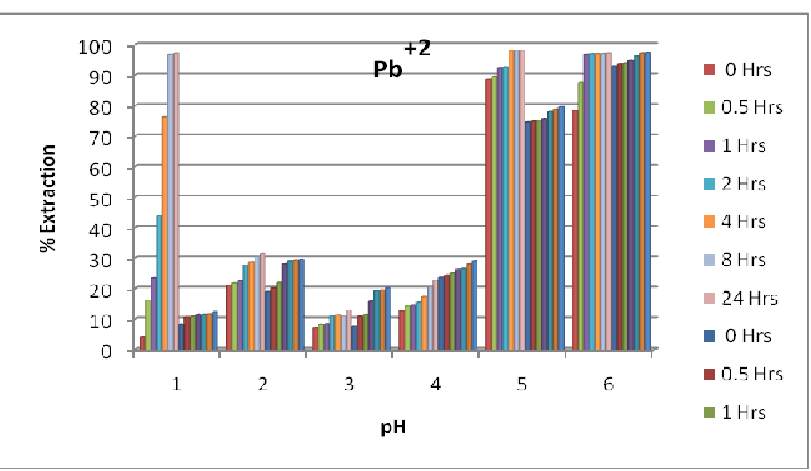

Fig. 4. \% Extraction of Cadmium Metal ion at different $p H$

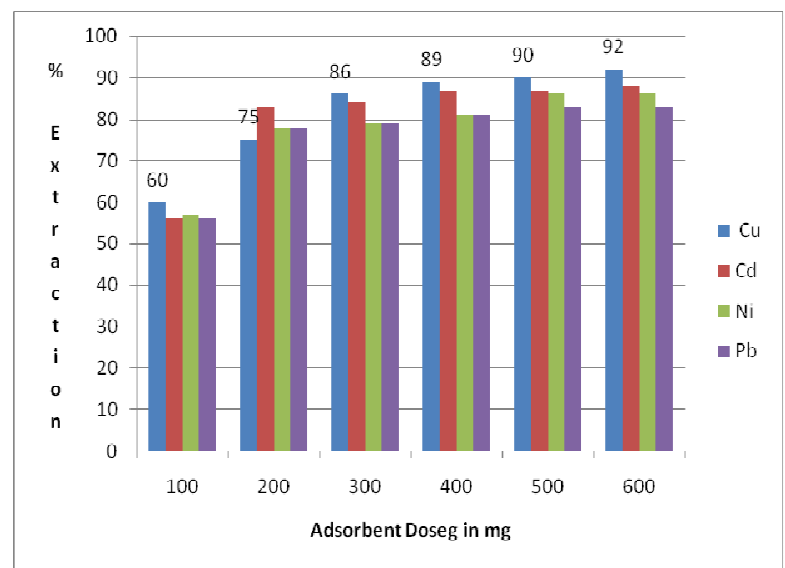

Fig. 5. Effect of adsorbent dose on the removal of Metal ion

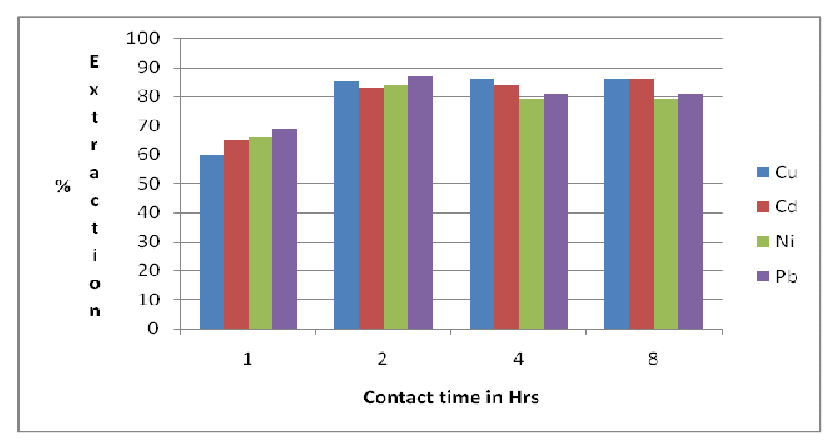

Fig. 6. Effect of contact time on the removal of Metal Ion

\section{Conclusion}

Natural bio polymer "Chitosan" based sorbent provides green route of metal extraction. The characterization of Chitosan -g-poly (acrylic acid-co-acryl amide) new sorbent 
material gives information about pore size, good chemical and thermal stability which revels applicability towards Metal extraction. This low-cost adsorbents are effective for the removal of metal ions from aqueous solutions shows order of $\%$ extraction i.e. $\mathrm{Cu}^{2+}>\mathrm{Cd}^{2+}>\mathrm{Ni}^{2+}>\mathrm{Pb}^{2+}$. The batch method was employed parameters such as $\mathrm{pH}$, contact time and metal concentration were studied at an ambient temperature $25^{\circ} \mathrm{C}$. The optimum $\mathrm{pH}$ corresponding to the maximum adsorption of copper, cobalt, nickel and lead removal was $\mathrm{pH}$ 5-6. Copper cobalt, nickel and lead ions were adsorbed onto the adsorbents very rapidly within the first $120 \mathrm{~min}$.

\section{Abbreviations}

AM, Acrylamide; AA, acrylic acid; MBA, methylenebisacrylamide APS, ammonium persulfate; SEM, scanning electron microscopy; DSC Differential Scanning Colourimentry ,FTIR, Fouirer transfer infra red spectroscopy, XRD X ray diffraction

\section{References}

[1] Monteagudo and Ortiz, Removal of inorganic mercury from mine waste water by ion exchange,Journal of Chemical Technology and Biotechnology (September 2000),Volume 75, Issue 9 , pages 767-772,

[2] G.R. Mahdavinia a, A. Pourjavadi a, *, H. Hosseinzadeh a, M.J. Zohuriaan b, Modified chitosan 4 Superabsorbent hydrogels from poly(acrylic acid-co-acrylamide) grafted chitosan,European Polymer Journal 40 (2004) 1399-1407.

[3] Dengshan Bao, Preparation and characterization of double crosslinked composites films from carboxymethylchitosan and carboxymethylcellulose Carbohydrate Polymers (September 2014), Volume 110, 22, Pages 113-120.

[4] Huixia SH, Wang W and Wang A, Modification of chitosan radiation-induced graft copolymerization of acrylonitrile onto chitosan, Appl. Clay Sci(2010), 50: 112 -117.
[5] Lin H, Zhou J, Yingde C, Gunasekaran S, Synthesis and characterization of $\mathrm{pH}$ - and salt-responsive composites based on etherificated sodium alginate, J. Appl. Polym. Sci. (2010),115: 3161-3167.

[6] Jia Liu, Qian Li, Yuan Su, Qinyan Yue, Bao yu Characterization and swelling-deswelling properties of wheat straw cellulose based semi-IPNs composite, Carbohydrate Polymers(17 July 2014)Volume 107, Pages 232-240.

[7] Pourjavadi A, Farhadpour B, Seidi F, Synthesis and investigation of swelling behavior of new agar based superabsorbent composite as a candidate for agrochemical delivery,J. Polym. Res (2009), 16: 655-665.

[8] Mohammad Sadeghi and Mojgan Yarahmadi, Synthesis and characterization of superabsorbent composite based on chitosan-g-poly (acrylic acid-co-acrylonitrile), African Journal of Biotechnology Vol. 10(57), pp. 12265-12275, 28.

[9] Chin-San Wu, A comparison of the structure, thermal properties, and biodegradability of polycaprolactone/chitosan and acrylic acid grafted polycaprolactone/chitosan ,Polymer (6 January 2005)Volume 46, Issue 1,, Pages 147-155.

[10] Prerna P. Dhawade and Ramanand N. Jagtap, Characterization of the glass transition temperature of chitosan and its oligomers by temperature modulated differential scanning calorimetry ,Advances in Applied Science Research, 2012, 3 (3):1372-1382.

[11] G.R. Mahdavinia, A. Pourjavadi a, H. Hosseinzadeh a, M.J. Zohuriaan Salt- and pH-Resisting Collagen-based Highly Porous Composite Polymer Journal, 2004.

[12] Mohammad Sadeghi and Mojgan Yarahmadi Synthesis of a Novel pH- and Salt-Responsive Super Absorbent Composite based on Collagen-g-poly(AA-co-IA).Oriental journal of chemistry, 2011.

[13] Omar E. Abdel Salam Neama A. Reiad, Maha M. ElShafei A study of the removal characteristics of heavy metals from wastewater by low-cost adsorbents,Journal of advance research, 2011.

[14] Gkarthikeyan, K anblagan N Andal Adsorption dynamics and equilibrium studies of Zn (II) onto chitosan J. Chem. Sci., Vol. 116, No. 2, March 2004, pp. 119-1272004. 